\title{
Close correlation between the ankle-brachial index and symptoms of depression in hemodialysis patients
}

\author{
Ing-Chin Jong ${ }^{1}$ Hung-Bin Tsai ${ }^{2}$ Chien-Hung Lin ${ }^{3,4}$ • Tsung-Liang Ma ${ }^{1}$. \\ How-Ran Guo ${ }^{5}$ Peir-Haur Hung ${ }^{1,6} \cdot$ Kuan-Yu Hung ${ }^{7}$
}

Received: 11 January 2017 / Accepted: 16 April 2017 / Published online: 28 April 2017

(C) The Author(s) 2017. This article is an open access publication

\begin{abstract}
Background As both of peripheral arterial disease (PAD) and depression carried a poor prognosis in patients on maintenance hemodialysis (MHD), we investigated the correlation between the ankle-brachial index (ABI), an indicator of subclinical PAD, and symptoms of depression in patients on MHD.

Methods One hundred and twenty-nine patients on MHD (75 males and 54 females, mean age $64.8 \pm 12$ years) were enrolled in this cross-sectional study, which aimed at evaluating the relationship between symptoms of depression and ABI. Demographic as well as clinical and laboratory variables including status of diabetes, chronic hepatitis $\mathrm{C}$ infection, dialysis duration, Charlson comorbidity index (CCI), plasma levels of albumin, C-peptide, insulin, high-sensitive $\mathrm{C}$-reactive protein (hsCRP), interleukin-6
\end{abstract}

Peir-Haur Hung

dtmedg3@yahoo.com.tw

Ing-Chin Jong

01345@cych.org.tw

Hung-Bin Tsai

hbtsai@ms32.hinet.net

Chien-Hung Lin

dan08@ tpech.gov.tw

Tsung-Liang Ma

matsungliang@gmail.com

How-Ran Guo

hrguo@mail.ncku.edu.tw

Kuan-Yu Hung

kyhung@ntu.edu.tw

Division of Nephrology, Department of Internal Medicine, Ditmanson Medical Foundation Chia-Yi Christian Hospital, 539 Jhongsiao Road, Chia-Yi City 600, Taiwan
(IL-6), adiponectin, and lipid profile were obtained. The self-administered beck depression inventory (BDI) was used to determine the presence or absence of symptoms of depression, and depression was defined as a BDI score $\geqq 14$. Multivariable-adjusted linear regression models were constructed to confirm the independent association of biologic parameters of symptoms of depression. Significance was defined as $P<0.05$. Statistical analyses were performed using SPSS/Windows software (SPSS Science, v. 15.0, Chicago, IL).

Results The mode of multivariate analysis showed that diabetes $(\beta=3.594 ; P=0.040)$, hepatitis $\mathrm{C}$ infection $(\beta=4.057 ; P=0.008)$, levels of serum albumin ( $\beta=-5.656 ; P=0.024)$, C-peptide $(\beta=-0.292$; $P=0.002)$, ABI $(\beta=-9.041 ; P=0.031)$, and Ln-transformed hsCRP were significantly associated with BDI.
2 Department of Tramatology, National Taiwan University Hospital, 7 Chung Shan S. Road, Zhongzheng Dist., Taipei City 10002, Taiwan

3 Institute of Clinical Medicine, National Yang-Ming University, 155 Linong Street, Taipei City 112, Taiwan

4 Department of Pediatrics, Zhongxing Branch, Taipei City Hospital, 145 Zhengzhou Road, Datong Dist., Taipei City 10341, Taiwan

5 Department of Environmental and Occupational Health Medical Colleage, National Cheng Kung University, No. 1 University Road, Tainan City 70401, Taiwan

6 Department of Applied Life Science and Health, Chia-Nan University of Pharmacy and Science, 60 Erren Road, Rende Dist., Tainan City 71710, Taiwan

7 Department of Internal Medicinem, National Taiwan University Hospital, Hsin-Chu Branch, 25 Jingguo Road, Hsin-Chu City 300, Taiwan 
Conclusions Hepatitis C infection, serum levels of albumin, C-peptide, and ABI levels were found to be correlated with BDI $(P<0.05)$.

Keywords Ankle-brachial index · Beck depression inventory $\cdot$ Depression $\cdot$ Hemodialysis

\section{Introduction}

Depression is highly prevalent throughout the world and is increasing in the range of $8-12 \%$ per year [1]. Among patients with chronic medical illness, the annual prevalence rate of depression is significantly higher, approximately $25 \%$ per year [2]. It is generally accepted by the practitioners that depression is the most common psychological problem in patients with end stage renal disease (ESRD) and patient on maintenance hemodialysis (MHD) with depression carries a poor prognosis [3]. Depression is often considered the final common pathway for different disease processes that occur across the biopsychosocial continuum. In patients with ESRD, contributing factors to the onset of depression include physical and emotional stress related to functional limitations, dietary constraints, time restrictions to dialysis, medical comorbidities, and adverse effects of medication [4-6].

MIA syndrome (malnutrition, inflammation, and atherosclerosis) may also contribute to the symptoms of depression in patients with ESRD. Recent available data suggest that peripheral arterial disease (PAD) is prevalent in hemodialysis (HD) patients and is a strong predictor for subsequent cardiovascular disease and overall mortality [7]. The ankle-brachial index (ABI) has been reported as a good marker for atherosclerosis and useful for the diagnosis of PAD [8]. Although traditional cardiovascular risk factors such as smoking, diabetes, hypertension, and hyperlipidemia have been proven to be strong risk factors for PAD in the general population [9], depression is associated with PAD in women, and is not unusual in the general population having suffered from PAD, and occurs in patients with diabetes [10-13].

Previous studies have shown that risk factors for depressive symptoms in patients on MHD may include poor sleep quality, pruritus, hypoalbuminemia, higher serum levels of IL-6, C-reactive protein, and comorbidities [14, 15]. However, the impact of PAD in the development of symptoms of depression in patients on MHD has not been evaluated. We currently hypothesize that ABI is correlated with the symptoms of depression in patients on MHD with the purpose of early detection of the risk factors of the depressive disorder in patients on MHD. Since depression is correlated with increased mortality rate in patients on MHD [3], identification of factors correlated with the symptoms of depression may allow clinicians to further optimize their treatment strategies.

\section{Materials and methods}

\section{Study population}

Two hundred and four patients with ESRD in a regional hospital St. Martin De Porres Hospital (Chiayi City, Taiwan) were recruited for this cross-sectional study.

\section{Inclusion and exclusion criteria}

\section{Inclusion criteria}

Those who had received HD treatment 3 times per week for greater than 3 months, with each session lasting for $4 \mathrm{~h}$, were included in this study. Informed consent was secured for all study subjects. This clinical study followed the Declaration of Helsinki and was approved by the Ethics Committee of St. Martin De Porres Hospital.

\section{Exclusion criteria}

Patients with irregular or inadequate HD therapy with a mean $\mathrm{Kt} / \mathrm{V}<1.2$, or with a HD duration $<3$ months before entry, or patients found to have major infections, amputation of lower extremity, an $\mathrm{ABI} \geqq 1.3$, or patients who had been taking immunosuppressive agents for at least 1 month were excluded. Patients with incomplete studies were also excluded.

\section{Study evaluations}

Demographic data such as age and sex were obtained using a questionnaire. Clinical characteristics, including medical comorbidities, current medications, and recent laboratory examinations were obtained using patient medical records. Charlson comorbidity index (CCI) was used to evaluate comorbid diseases severity in enrolled patients [16]. The beck depression inventory (BDI) was distributed by a healthcare assistant during a HD session, and the score for BDI was self-administered and self-reported. The presence and/or severity of depression was categorized by BDI score for the general population without ESRD: depression symptoms (14-63) and non-depression symptoms (0-13), owing to the absence of standard BDI categories for patients with ESRD [17].

Hematological and biochemical parameters were evaluated using blood obtained from midweek pre-dialysis samples. Plasma samples were separated from blood cells and stored at $-70{ }^{\circ} \mathrm{C}$. Venous blood samples were collected the 
morning after an overnight fast. Samples were centrifuged at $1500 \times g$ at $4{ }^{\circ} \mathrm{C}$ for $10 \mathrm{~min}$ for analysis. Kt/V was calculated using Daugirdas' second formula [18].

Hematologic levels were measured using Sysmex XT-1800i hematology analyzer (Sysmex America Inc., Mundelein, IL). Levels of serum high-sensitivity C-reactive protein (hsCRP) and insulin were measured using a chemiluminescent immunoassay (Immulite 2000; DPC, Los Angeles, CA). Insulin sensitivity was quantified using the homeostasis model assessment of insulin resistance (HOMA-IR) equation to measure fasting insulin and glucose levels (HOMA-IR $=\mathrm{I} \times 3 \mathrm{G} / 22.5$ ), where ' $\mathrm{I}$ ' is insulin (IU/mL) and ' $\mathrm{G}$ ' is glucose (mmol/L) (IR: HOMAindex $\geqq 2.5 \mu \mathrm{U} / \mathrm{mL} \times \mathrm{mmol} / \mathrm{L}$ ) [19]. Levels of serum C-peptide were measured using two-site sandwich immunoassay automated chemiluminescence system (Bayer ADVIA Centaur XP). Fasting blood sugar, calcium, phosphate, albumin, glutamic pyruvic transaminase (GPT), cholesterol, and triglyceride levels were measured using an automated analyzer (Hitachi 7170, Tokyo, Japan). Serum intact parathyroid hormone (iPTH) levels were measured using immunoradiometric assays (Nichols Institute Diagnostics, San Juan Capistrano, CA, USA). For hsCRP, the intra-assay coefficient of variance was $8.7 \%$, sensitivity was $0.1 \mathrm{mg} / \mathrm{L}$, and upper limit of detection was $150 \mathrm{mg} / \mathrm{L}$ [20]. Expected values for healthy individuals were hsCRP $\leqq 3 \mathrm{mg} / \mathrm{L}$ [21]. Serum proinflammatory cytokine levels were measured using a high-sensitivity interleukin (IL)-6, tumor necrosis factor (TNF)- $\alpha$, and adiponectin immunoassay kits. These measurements were based on a solidphase sandwich enzyme-linked immunoassay with TNF- $\alpha$ (normal range 0.5-100 pg/mL; RayBiotech), recombinant human IL-6 (normal range 0.03-200 pg/mL; RayBiotech, Atlanta, GA), and adiponectin (normal range $0.5-100 \mathrm{pg} /$ $\mathrm{mL}$; RayBiotech). Anti-hepatitis C virus (Anti-HCV) antibodies were measured using a third-generation enzyme immunoassay (Abbott Laboratories, North Chicago, IL).

The ABI index and pulse wave velocity (PWV) were measured in all patients by applying a vascular screening device (VP 1000; Colin Corp Co, Ltd, Komaki, Japan) that simultaneously measures bilateral arm and ankle (brachial and posterior tibial arteries, respectively) blood pressure. Measurements of both the ABI index and PWV were obtained after completion of the dialysis treatment and after allowing patients to rest in a supine position for at least $5 \mathrm{~min}$. Some patients required more than $10 \mathrm{~min}$ for their blood pressure to stabilize. ABI was calculated using the ratio of ankle systolic pressure to arm systolic pressure. Both the systolic pressure of the arm without dialysis access and the lower value of the ankle pressure were used to calculate the ABI index. The ABI index for each patient was checked at least twice during each dialysis session, with the mean used for subsequent analysis. A diagnosis of PAD required an $\mathrm{ABI}<0.9$, which may be indicative of varying degrees of atherosclerosis in the arteries of the lower extremity. Patients with an $\mathrm{ABI} \geqq 1.3$ were excluded, because this implies poorly compressible leg arteries and inability to accurately gauge arterial obstruction [7]. For measuring PWV, pulse waves obtained from the brachial and tibial arteries were recorded simultaneously, and the transmission time, defined as the time interval between the initial increase in brachial and tibial waveforms, was determined. The transmission distance from the arm to each ankle was calculated according to body height. The PWV value was automatically computed as the transmission distance divided by the transmission time. After obtaining bilateral PWV values, the highest one was used as representative for each subject. The PWV measurement was done once in each patient.

\section{Statistical analysis}

Continuous variables were expressed as mean $\pm \mathrm{SD}$, and categorical variables were expressed as percentages. Data were analyzed using a $t$ test or $\chi^{2}$ test, depending on the nature of the variables. Proinflammatory cytokine concentration was Ln-transformed to improve its level of normality. A Spearman's correlation analysis was performed to evaluate the relationship between biological markers and symptoms of depression. Multivariable-adjusted linear regression models were constructed to confirm the independent association of biologic parameters of symptoms of depression. Significance was defined as $P<0.05$. Statistical analyses were performed using SPSS/Windows software (SPSS Science, v. 15.0, Chicago, IL).

\section{Results}

As shown in the study flow diagram Fig. 1, a total of 204 patients were recruited, of which four patients with hemodialysis duration less than 3 months, two patients with $\mathrm{Kt} / \mathrm{V}$ less than 1.2 , two patients with $\mathrm{ABI} \geqq 1.3$, eight patients with amputation of lower extremity, 59 patients with incomplete studies including 37 patients without data of serum C-peptide levels, 6 patients without data of serum iPTH levels, 7 patients without data of serum insulin levels, 7 patients without data of serum hsCRP levels, and 2 patients without data of serum IL-6 levels were excluded. The resulting 129 patients were enrolled in the study. Among enrolled patients, $33.3 \%$ were depressed and $66.7 \%$ were not depressed (non-depressed), respectively (Table 1). Clinical and biochemical characteristics in depressed and non-depressed HD patients are summarized in Table 1. HD patients in depressed group were significantly older than the non-depressed group $(66.7 \pm 10.1$ vs. $60.8 \pm 13.9$; 


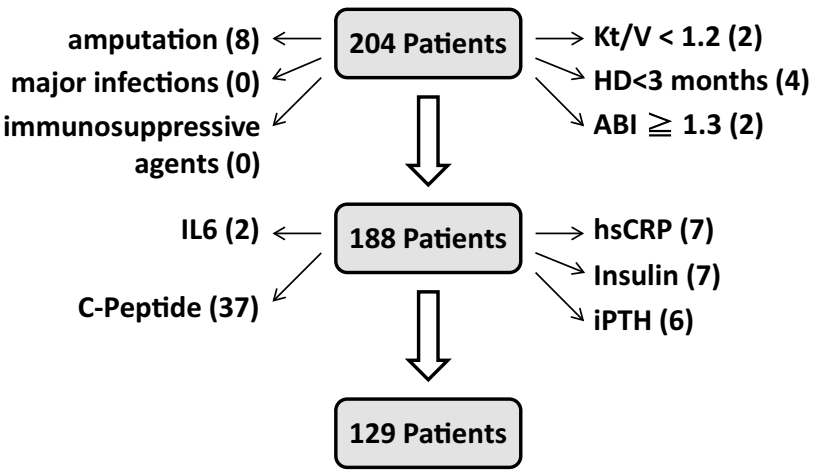

Fig. 1 Study flow diagram

$P=0.007)$. The depressed group had a significantly higher prevalence of hepatitis C (58.1 vs. 39.5\%; $P=0.046)$ and diabetes $(74.4$ vs. $39.5 \% ; P<0.001)$ compared with the non-depressed group. The biochemical examination showed that depressed patients had significantly lower levels of albumin ( $3.7 \pm 0.3$ vs. $4.0 \pm 0.4 ; P<0.001)$, C-peptide $(10.6 \pm 6.5$ vs. $13.6 \pm 10.3 ; P=0.044)$, and ABI $(0.96 \pm 0.2$ vs. $1.04 \pm 0.2 ; P=0.028)$ compared with the non-depressed group. The distribution of the status of ABI and BDI scores was demonstrated in Fig. 2. Higher CCI scores $(4.0 \pm 2.3)$ found in the depressed group than that found in the non-depressed group CCI scores $(2.5 \pm 2.2)$ are indicative of the association of depression with CCI scores in patients on MHD. Levels of depression and the other related variables in HD patients are reported in Table 2 . The BDI was found to be positively correlated with age $(r=0.348 ; P<0.001)$ and CCI $(r=0.387 ; P<0.001)$. In addition, BDI was significantly negatively correlated with levels of serum albumin $(r=-0.399 ; P<0.001)$ and ABI $(r=-0.325 ; P<0.001)$. The mode of multivariate analysis showed that diabetes $(\beta=3.594 ; P=0.040)$,
Table 1 Differences of clinical and biochemical parameters between depressed and nondepressed hemodialysis patients

\begin{tabular}{|c|c|c|c|}
\hline & $\mathrm{BDI}<14(n=86)$ & $\mathrm{BDI} \geqq 14(n=43)$ & $P$ value \\
\hline Age (years) & $60.8 \pm 13.9$ & $66.7 \pm 10.1$ & $0.007 *$ \\
\hline Male (\%) & $50(58.1 \%)$ & $25(58.1 \%)$ & 1.000 \\
\hline Dialysis duration (years) & $4.8 \pm 3.9$ & $5.0 \pm 4.3$ & 0.721 \\
\hline Body mass index $\left(\mathrm{kg} / \mathrm{m}^{2}\right)$ & $23.1 \pm 4.0$ & $22.9 \pm 3.1$ & 0.775 \\
\hline Systolic blood pressure (mmHg) & $139.9 \pm 19.6$ & $136.3 \pm 14.8$ & 0.289 \\
\hline Diastolic blood pressure $(\mathrm{mmHg})$ & $75.9 \pm 8.4$ & $75.4 \pm 6.0$ & 0.719 \\
\hline Hepatitis C infection (\%) & $34(39.5 \%)$ & $25(58.1 \%)$ & $0.046^{*}$ \\
\hline Diabetes $(\%)$ & $34(39.5 \%)$ & $32(74.4 \%)$ & $<0.001^{*}$ \\
\hline Albumin (g/dl) & $4.0 \pm 0.4$ & $3.7 \pm 0.3$ & $<0.001^{*}$ \\
\hline Hemoglobulin (gm/dl) & $10.4 \pm 1.5$ & $10.4 \pm 1.7$ & 1.000 \\
\hline ALT (U/L) & $18.8 \pm 12.8$ & $29.4 \pm 56.3$ & 0.231 \\
\hline Fasting blood glucose (mg/dl) & $113.5 \pm 63.2$ & $131.8 \pm 71.6$ & 0.141 \\
\hline Insulin $(\mu \mathrm{IU} / \mathrm{ml})$ & $23.5 \pm 33.3$ & $25.8 \pm 37.2$ & 0.726 \\
\hline C-peptide (ng/mL) & $13.6 \pm 10.3$ & $10.6 \pm 6.5$ & $0.044 *$ \\
\hline HOMA-IR $(\mu \mathrm{U} / \mathrm{mL} \times \mathrm{mmol} / \mathrm{L})$ & $6.2 \pm 7.3$ & $8.6 \pm 10.9$ & 0.140 \\
\hline iPTH (pg/mL) & $187.2 \pm 171.5$ & $165.1 \pm 169.1$ & 0.490 \\
\hline $\mathrm{Ca} \times \mathrm{P}\left(\mathrm{mg}^{2} / \mathrm{dL}^{2}\right)$ & $42.6 \pm 13.9$ & $42.2 \pm 14.3$ & 0.871 \\
\hline Total cholesterol (mg/dl) & $170.9 \pm 38.3$ & $157.9 \pm 36.7$ & 0.067 \\
\hline Triglyceride (mg/dl) & $167.4 \pm 119.2$ & $153.2 \pm 123.1$ & 0.528 \\
\hline HDL cholesterol (mg/dl) & $44.5 \pm 13.6$ & $44.2 \pm 16.3$ & 0.911 \\
\hline LDL cholesterol (mg/dl) & $97.8 \pm 27.2$ & $91.4 \pm 23.7$ & 0.196 \\
\hline Ln_hsCRP (mg/dL) & $1.33 \pm 1.28$ & $1.34 \pm 1.30$ & 0.991 \\
\hline Ln_Adiponectin (pg/mL) & $5.6 \pm 0.3$ & $5.7 \pm 0.3$ & 0.063 \\
\hline Ln_IL-6 (pg/mL) & $2.8 \pm 1.0$ & $3.0 \pm 0.8$ & 0.488 \\
\hline Ln_TNF- $\alpha(p g / m L)$ & $0.84 \pm 0.96$ & $0.82 \pm 0.96$ & 0.941 \\
\hline $\mathrm{CCI}$ & $2.5 \pm 2.2$ & $4.0 \pm 2.3$ & $<0.001 *$ \\
\hline $\mathrm{ABI}$ & $1.04 \pm 0.20$ & $0.96 \pm 0.20$ & $0.028 *$ \\
\hline $\mathrm{PWV}(\mathrm{m} / \mathrm{s})$ & $17.9 \pm 5.7$ & $18.4 \pm 5.1$ & 0.661 \\
\hline
\end{tabular}

$A B I$ ankle-brachial index, $B D I$ beck depression inventory, $C C I$ Charlson comorbidity index; $h s C R P$ highsensitivity $\mathrm{C}$-reactive protein

$* P<0.05$ 
Fig. 2 Scatterplots diagram demonstrated the distribution between the status of $\mathrm{ABI}$ and the BDI scores. The difference of the status of ABI between patients with BDI scores $\geqq 14$ and those with BDI scores $<14$ is statistically significant $(P<0.05)$

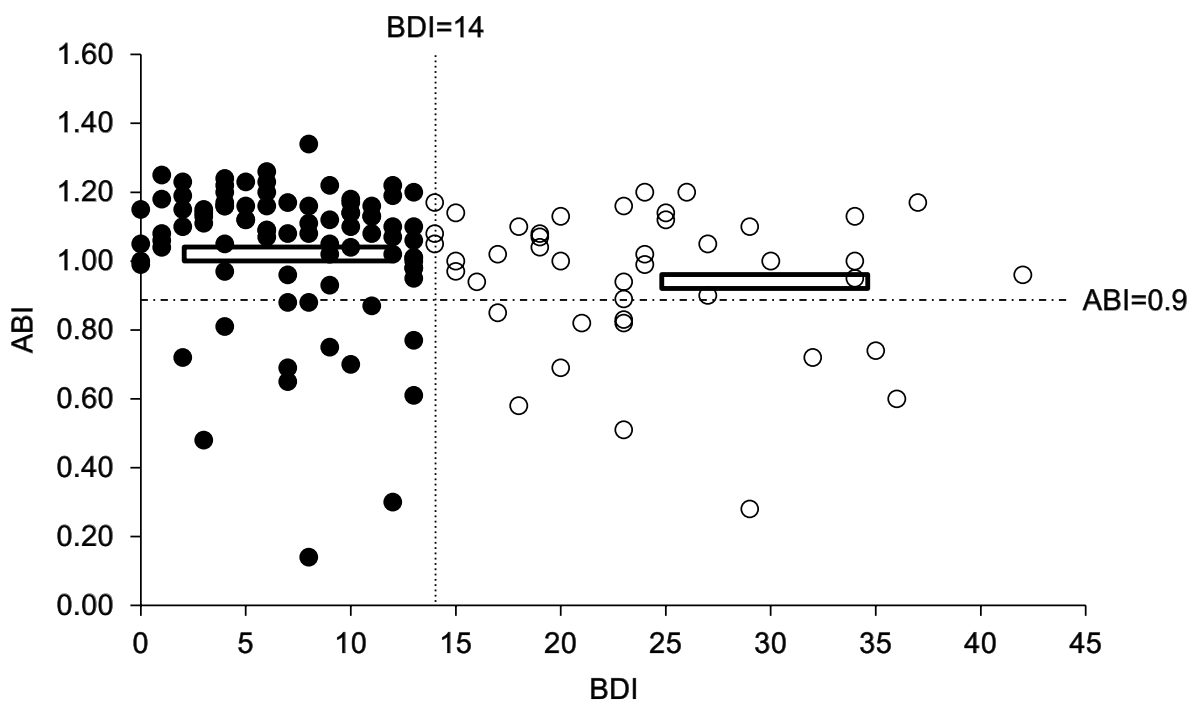

Table 2 Spearman rank correlation between BDI levels and the other variables in hemodialysis patients $(n=129)$

\begin{tabular}{lcc}
\hline & $r$ & $P$ value \\
\hline Age & 0.348 & $<0.001^{*}$ \\
Body mass index $\left(\mathrm{kg} / \mathrm{m}^{2}\right)$ & -0.044 & 0.619 \\
CCI & 0.387 & $<0.001^{*}$ \\
Blood pressure & & \\
Systolic & -0.078 & 0.380 \\
Diastolic & -0.064 & 0.474 \\
Albumin $(\mathrm{g} / \mathrm{dl})$ & -0.399 & $<0.001^{*}$ \\
Glucose & 0.090 & 0.311 \\
Plasma lipids & & \\
LDL & -0.115 & 0.193 \\
HDL & -0.050 & 0.575 \\
Triglycerides & -0.121 & 0.172 \\
Insulin $(\mu \mathrm{IU} / \mathrm{ml})$ & 0.044 & 0.626 \\
C-peptide $(\mathrm{ng} / \mathrm{mL})$ & -0.175 & $0.047^{*}$ \\
HOMA-IR $(\mu \mathrm{U} / \mathrm{mL} \times \mathrm{mmol} / \mathrm{L})$ & 0.076 & 0.391 \\
ABI & -0.325 & $<0.001^{*}$ \\
PWV $(\mathrm{m} / \mathrm{s})$ & 0.098 & 0.271 \\
Ln_hsCRP $(\mathrm{mg} / \mathrm{dL})$ & 0.015 & 0.869 \\
Ln_TNF- $\alpha(\mathrm{pg} / \mathrm{mL})$ & -0.063 & 0.480 \\
Ln_IL-6 $(\mathrm{pg} / \mathrm{mL})$ & 0.143 & 0.105 \\
Ln_Adiponectin $(\mathrm{pg} / \mathrm{mL})$ & 0.160 & 0.069 \\
\hline
\end{tabular}

$A B I$ ankle-brachial index; $B D I$ beck depression inventory, $C C I$ Charlson comorbidity index; $h s C R P$ high-sensitivity $\mathrm{C}$-reactive protein, $P W V$ pulse wave velocity

$* P<0.05$

hepatitis $\mathrm{C}$ infection $(\beta=4.057 ; P=0.008)$, levels of serum albumin $(\beta=-5.656 ; P=0.024)$, C-peptide $(\beta=-0.292 ; P=0.002)$, ABI $(\beta=-9.041 ; P=0.031)$, and Ln-transformed hsCRP were significantly associated
Table 3 Multivariable-adjusted linear regression analysis for the BDI score $(n=129)$

\begin{tabular}{lcl}
\hline Variables & \multicolumn{2}{l}{ Multivariate } \\
\cline { 2 - 3 } & Coefficient $(\beta)$ & $P$ value \\
\hline Male gender & -0.849 & 0.593 \\
Age (years) & 0.011 & 0.874 \\
Diabetes & 3.594 & $0.040^{*}$ \\
Hepatitis C infection & 4.057 & $0.008^{*}$ \\
Albumin (g/dl) & -5.656 & $0.024^{*}$ \\
C-peptide & -0.292 & $0.002^{*}$ \\
ABI & -9.041 & $0.031^{*}$ \\
HOMA-IR & -0.015 & 0.914 \\
Ln_hsCRP & -1.391 & $0.044^{*}$ \\
Insulin & 0.032 & 0.331 \\
Ln_IL-6 & 1.126 & 0.231 \\
Ln_TNF- $\alpha$ & -0.843 & 0.306 \\
\hline
\end{tabular}

$A B I$ ankle-brachial index, $B D I$ beck depression inventory

$* P<0.05$

with BDI as shown in Table 3. However, gender and age were not found to be associated with BDI.

\section{Discussion}

In the current analysis of BDI scores, serum levels of albumin, C-peptide, chronic hepatitis $\mathrm{C}$ infection, diabetes, and $\mathrm{ABI}$ were all demonstrated to be correlated with symptoms of depression in patients on MHD. To the best of our knowledge, these results provide the first evidence for an association of ABI with symptoms of depression in patients on MHD.

Regardless of the statistical analysis used to obtain BDI score, patients with a BDI $\geqq 14$ had significantly 
lower serum albumin levels compared with patients with a BDI $<14$. Previous studies have revealed a correlation between serum albumin levels with symptoms of depression in patients on MHD $[14,15]$. Malnutrition in dialysis patients was not caused by poor intake alone, but also was the result of chronic inflammation [22]. In an animal model, it has been suggested that nuclear factor-kappa B (NF-kB) caused decreased albumin gene expression in states of inflammation, leading to a decreased rate of albumin synthesis and a reduced serum albumin concentration [23]. And in human study, it showed decreased liver synthesis of albumin in inflammation [24]. In the general population or for patients on MHD, infection with chronic hepatitis $\mathrm{C}$ has been demonstrated to be correlated with symptoms of depression $[25,26]$, consistent with the current findings.

It has been previously demonstrated that diabetic patients have a double risk of depression as compared to the nondiabetic group [27]. Furthermore, in patients on MHD, the presence of diabetes is significantly associated with symptoms of depression [14]. The current study also demonstrated that diabetes was correlated with the symptoms of depression in patients on MHD after the mode of the multivariable-adjusted linear regression analysis for the BDI score. C-peptide and insulin are secreted in equal amounts, and clinically monitoring of serum levels of C-peptide is considered to be a valid measure of insulin secretion in diabetic patients [28]. We suspect that diabetic patients with lower C-peptide serum levels and lower levels of endogenous insulin secretion might suffer from much more beta-cell failure due to the longer duration of illness associated with diabetes. Consistent with this previous report, we currently demonstrate a correlation between lower levels of serum C-peptide with symptoms of depression in patients on MHD.

A possible link between ABI and symptoms of depression in patients on MHD has been established. Smoking, diabetes, hypoalbuminemia, and dialysis duration have been demonstrated to be risk factors for PAD in patients on MHD [29, 30]. We also reported that diabetes, hypoalbuminemia, and serum levels of C-peptide were correlated with symptoms of depression in patients on MHD; however, they were also risk factors for PAD in patients on MHD. PAD and depression might be closely correlated, intimately interacting physiologically and psychologically. Also, in another point of view, the probable molecular link between ABI and BDI score might be through the proinflammatory cytokines IL- 6 and CRP, influencing both the vasculature and brain. The reasons were as follows. Firstly, a prospective population-based cohort study by Tzoulaki et al. [31] demonstrated that the serum level of C-reactive protein (CRP) was not only correlated with PAD severity at baseline but also a predictor of progression of PAD in the general population. And our previous study also showed that IL-6 (a precursor of CRP) was associated with PAD in patients on MHD [32]. Secondly, in a prospective, populationbased cohort study by Khandaker et al. [33], they demonstrated that children with higher serum levels of IL-6 and CRP would be exposed to increased future risks of depression and psychosis in young adulthood in a dosedependent way. And previous study by Hung et al. [15] also revealed that serum levels of IL-6 and hsCRP were associated with symptoms of depression in patients on MHD. So, ABI and BDI scores might be closely correlated. MIA syndrome could be associated with the symptoms of depression in patients on MHD. Taken together, we demonstrated a correlation between $\mathrm{ABI}$ and the symptoms of depression in patients on MHD.

Limitations of the current study include the lack of inferences on causality due to the cross-sectional nature of the study; therefore, implications on possible mechanisms should be regarded as hypotheses. Secondly, the study was monocentric with a small number of enrolled subjects; however, we would like to emphasize that all subjects were diagnosed from a large HD population screened for symptoms of depression and PAD and the symptoms of PAD were asymptomatic and the presence of an initial disorder of the arteries in the lower limbs was unknown. Thirdly, the presence and/or severity of depression was categorized by using the BDI score, instead of a clinician-administered structured diagnostic interview, and there might be some misclassifications.

\section{Conclusions}

In conclusion, to our knowledge, this is the first study providing evidence that $\mathrm{ABI}$ is closely correlated with symptoms of depression in patients on MHD. Furthermore, patients on MHD with symptoms of depression may have lower serum C-peptide, lower serum albumin levels, and lower ABI levels. Factors including diabetes, hepatitis $\mathrm{C}$ infection, and $\mathrm{ABI}$ levels may predispose the development of symptoms of depression. Further study is required to evaluate the association between depression and other health-related outcomes, including PAD.

Acknowledgements The authors would also like to acknowledge the support of Dr. Tsung-Hsien Chen in the preparation of this manuscript.

\section{Compliance with ethical standards}

Conflict of interest All other authors have declared no competing interests. 
Open Access This article is distributed under the terms of the Creative Commons Attribution 4.0 International License (http://creativecommons.org/licenses/by/4.0/), which permits unrestricted use, distribution, and reproduction in any medium, provided you give appropriate credit to the original author(s) and the source, provide a link to the Creative Commons license, and indicate if changes were made.

\section{References}

1. Weissman MM, Bland RC, Canino GJ, Faravelli C, Greenwald S, Hwu HG, Joyce PR, Karam EG, Lee CK, Lellouch J, Lépine JP, Newman SC, Rubio-Stipec M, Wells JE, Wickramaratne PJ, Wittchen H, Yeh EK (1996) Cross-national epidemiology of major depression and bipolar disorder. JAMA 276(4):293-299

2. Meader N, Mitchell AJ, Chew-Graham C, Goldberg D, Rizzo M, Bird V, Kessler D, Packham J, Haddad M, Pilling S (2011) Case identification of depression in patients with chronic physical health problems: a diagnostic accuracy meta-analysis of 113 studies. Br J Gen Pract 61(593):e808-e820. doi:10.3399/ bjgp11X613151

3. Kimmel PL, Peterson RA, Weihs KL, Simmens SJ, Alleyne S, Cruz I, Veis JH (2000) Multiple measurements of depression predict mortality in a longitudinal study of chronic hemodialysis outpatients. Kidney Int 57(5):2093-2098. doi:10.1046/j.1523-1755.2000.00059.x

4. Kimmel PL (2002) Depression in patients with chronic renal disease: what we know and what we need to know. J Psychosom Res 53(4):951-956. doi:10.1016/S0022-3999(02)00310-0

5. Jablonski A (2007) The multidimensional characteristics symptoms reported by patients on hemodialysis. Nephrol Nurs J 34(1):29-37

6. Son YJ, Choi KS, Park YR, Bae JS, Lee JB (2009) Depression, symptoms and quality of life in patients on hemodialysis for end-stage renal disease. Am J Nephrol 29(1):36-42. doi: $10.1159 / 000150599$

7. Ono K, Tsuchida A, Kawai H, Matsuo H, Wakamatsu R, Maezawa A, Yano S, Kawada T, Nojima Y (2003) Ankle-brachial pressure index predicts all-cause and cardiovascular mortality in hemodialysis patients. J Am Soc Nephrol 14(6):15911598. doi:10.1097/01.ASN.0000065547.98258.3D

8. Fishbane S, Youn S, Kowalski EJ, Frei GL (1995) Ankle-arm blood pressure index as a marker for atherosclerotic cardiovascular diseases in hemodialysis patients. Am J Kidney Dis 25(1):3439. doi:10.1016/0272-6386(95)90622-3

9. Selvin E, Erlinger TP (2004) Prevalence of and risk factors for peripheral arterial disease in the United States: results from the National Health and Nutrition Examination Survey, 1999-2000. Circulation 110(6):738-743. doi:10.1161/01. CIR.0000137913.26087.F0

10. Grenon SM, Cohen BE, Smolderen K, Vittinghoff E, Whooley MA, Hiramoto J (2014) Peripheral arterial disease, gender and depression in the Heart and Soul Study. J Vasc Surg 60(2):396403. doi:10.1016/j.jvs.2014.02.013

11. Smolderen KG, Aquarius AE, de Vries J, Smith OR, Hamming JF, Denollet J (2008) Depressive symptoms in peripheral arterial disease: a follow-up study on prevalence, stability and risk factors. J Affect Disord 110(1-2):27-35. doi:10.1016/j. jad.2007.12.238

12. Williams LH, Rutter CM, Katon WJ, Reiber GE, Ciechanowski P, Heckbert SR, Lin EH, Ludman EJ, Oliver MM, Young BA, Von Korff M (2010) Depression and incident foot ulcer: a prospective cohort study. Am J Med 123(8):748.e3-754.e3. doi:10.1016/j.amjmed.2010.01.023
13. Bruce DG, Davis WA, Cetrullo V, Starkstein SE, Davis TM (2013) Clinical impact of the temporal relationship between depression and type 2 diabetes: the Fremantle diabetic study phase II. PLoS ONE 8(12):e81254. doi:10.1371/journal. pone.0081254

14. Araujo SM, de Bruin VM, Daher Ede F, Almeida GH, Medeiros CA, de Bruin PF (2012) Risk factors for depressive symptoms in a large population on chronic hemodialysis. Int Urol Nephrol 44(4):1229-1235. doi:10.1007/s11255-011-0032-9

15. Hung KC, Wu CC, Chen HS, Ma WY, Tseng CF, Yang LK, Hsieh HL, Lu KC (2011) Serum IL-6, albumin, and comorbidities are closely correlated with symptoms of depression in patients on maintenance haemodialysis. Nephrol Dial Transplant 26(2):658-664. doi:10.1093/ndt/gfq411

16. Charlson ME, Pompei P, Ales KL, MacKenzie CR (1987) A new method of classifying prognostic comorbidity in longitudinal studies: development and validation. J Chronic Dis 40(5):373-383. doi:10.1016/0021-9681(87)90171-8

17. Watnick S, Wang PL, Demadura T, Ganzini L (2005) Validation of 2 depression screening tools in dialysis patients. Am J Kidney Dis 46(5):919-924. doi:10.1053/j.ajkd.2005.08.006

18. Daugirdas JT, Van Stone JC (2001) Physiological principles and urea kinetic modeling. In: Daugirdas JT, Blake PG, Ing TS (eds) Handbook of Daugirdas, 3rd edn. Lippincott Wiliams \& Wilkins Press, Philadephia, pp 15-45

19. de Vinuesa SG, Goicoechea M, Kanter J, Puerta M, Cachofeiro V, Lahera V, Gómez-Campderá F, Luño J (2006) Insulin resistance, inflammatory biomarkers, and adipokines in patients with chronic kidney disease: effects of angiotensin II blockade. J Am Soc Nephrol 17(12 Suppl 3):S206-S212. doi:10.1681/ ASN.2006080916

20. Tarkun I, Cetinarslan B, Türemen E, Sahin T, Cantürk Z, Komsuoglu B (2005) Effects of rosiglitazone on insulin resistance, $\mathrm{C}$-reactive protein and endothelial function in nonobese young women with polycystic ovary syndrome. Eur J Endocrinol 153(1):115-121. doi:10.1530/eje.1.01948

21. Komulainen P, Lakka TA, Kivipelto M, Hassinen M, Penttilä IM, Helkala EL, Gylling H, Nissinen A, Rauramaa R (2007) Serum high sensitivity C-reactive protein and cognitive function in elderly women. Age Ageing 36(4):443-448. doi:10.1093/ageing/afm051

22. Stenvinkel $P$, Heimbürger $O$, Paultre F, Diczfalusy U, Wang T, Berglund L, Jogestrand T (1999) Strong association between malnutrition, inflammation, and atherosclerosis in chronic renal failure. Kidney Int 55(5):1899-1911. doi:10.1046/j.1523-1755.1999.00422.x

23. Guttridge DC, Mayo MW, Madrid LV, Wang CY, Baldwin AS Jr (2000) NF-kappaB-induced loss of MyoD messenger RNA: possible role in muscle decay and cachexia. Science 289(5488):2363-2366. doi:10.1126/science.289.5488.2363

24. Moshage HJ, Janssen JA, Franssen JH, Hafkenscheid JC, Yap SH (1987) Study of the molecular mechanism of decreased liver synthesis of albumin in inflammation. J Clin Invest 79(6):1635-1641. doi:10.1172/JCI113000

25. Foster GR, Goldin RD, Thomas HC (1998) Chronic hepatitis c virus infection causes a significant reduction in quality of life in the absence of cirrhosis. Hepatology 27(1):209-212. doi: 10.1002/hep.510270132

26. Afsar B, Elsurer R, Sezer S, Ozdemir NF (2009) Quality of life in hemodialysis patients: hepatitis $\mathrm{C}$ infection makes sense. Int Urol Nephrol 41(4):1011-1019. doi:10.1007/ s11255-009-9576-3

27. Anderson RJ, Freedland KE, Clouse RE, Lustman PJ (2001) The prevalence of comorbid depression in adults with diabetes. Diabetes Care 24(6):1069-1078. doi:10.2337/ diacare.24.6.1069 
28. Jones AG, Hattersley AT (2013) The clinical utility of c-peptide measurement in the case of patients with diabetes. Diabet Med 30(7):803-817. doi:10.1111/dme.12159

29. Cheung AK, Sarnak MJ, Yan G, Dwyer JT, Heyka RJ, Rocco MV, Teehan BP, Levey AS (2000) Atherosclerotic cardiovascular disease risks in chronic hemodialysis patients. Kidney Int 58(1):353-362. doi:10.1046/j.1523-1755.2000.00173.x

30. O'Hare AM, Hsu CY, Bacchetti P, Johansen KL (2002) Peripheral vascular disease risk factors among patients undergoing hemodialysis. J Am Soc Nephrol 13(2):497-503

31. Tzoulaki I, Murray GD, Lee AJ, Rumley A, Lowe GD, Fowkes FG (2005) C-reactive protein, interleukin-6, and soluble adhesion molecule are predictors of progressive peripheral atherosclerosis in the general population: Edinburgh Artery Study. Circulation 112:976-983. doi:10.1161/CIRCULATIONAHA.104.513085

32. Hung PE, Tsai HB, LinOH Hung KY (2013) Abdominal obesity is associated with peripheral artery disease in hemodialysis patients. PLoS ONE 8(6):e67555. doi:10.1371/journal. pone.0067555

33. Khandaker GM, Pearson RM, Zammit S, Lewis G, Jones PB (2014) Association of serum interleukin-6 and c-reactive protein in childhood with depression and psychosis in young adult life: a population-based longitudinal study. JAMA Psychiatry 71(10):1121-1128. doi:10.1001/jamapsychiatry.2014.1332 